\title{
Response of the Insulin-Like Growth Factor System to Vitamin A Depletion and Repletion in Rats
}

\author{
Zhengwei Fu, Miyako Yoneyama, Tadashi Noguchi ${ }^{1}$ and Hisanori Kato* \\ Department of Applied Biological Chemistry, Graduate School of Agricultural and Life Sciences, The University of Tokyo, \\ Yayoi 1-1-1, Bunkyo-ku, Tokyo 113-8657, Japan \\ ${ }^{1}$ Department of Biological Chemistry, College of Bioscience and Biotechnology, \\ Chubu University, Kasugai 487-8501, Japan
}

(Received July 26, 2002)

\begin{abstract}
Summary Vitamin A (VA) and insulin-like growth factors (IGF) are important regulators of a wide range of physiological processes. To investigate the IGF system's involvement in the physiological actions of VA, we examined the effects of VA status on components of the IGF system in rats. Male rats (3-wk-old) fed a VA-deficient diet for $11 \mathrm{wk}$ developed VA deficiency, as confirmed by the depletion of serum retinol and hepatic retinyl palmitate. Rats fed the VA-deficient diet had significantly lower body weight $(p<0.05)$ and lower serum IGF-I concentrations than the rats fed the control diet. The decreases in serum IGF-I levels were accompanied by approximately $40 \%$ lower levels of the IGF-I mRNA in the liver and lungs. With respect to the gene expression of other IGF system components, VA deficiency caused a twofold induction of IGF-I receptor (IGF-IR) mRNA in the heart and a twofold reduction in IGFBP-6 mRNA in the lungs, but did not alter the expression of IGF-II, IGFBP-1, IGFBP-3, IGFBP-4 or IGFBP- 5 in all tissues examined. When VA-deficient rats received a single injection of retinoic acid ( $2 \mathrm{mg} / \mathrm{rat}$ ), tissue IGF-I and IGF-IR gene expression did not change after 4 or $8 \mathrm{~h}$, while the expression of IGF-II, IGFBP-4, and IGFBP- 6 mRNAs in some tissues increased rapidly. These results suggest a possible involvement of the IGF system in mediating the physiological actions of VA, including VA-supported growth, in the rat.
\end{abstract}

Key Words vitamin A, insulin-like growth factor (IGF), IGF binding protein, IGF receptor, rat

Vitamin A (VA), a class of compounds including retinol, retinoic acid (RA), and other derivatives, is essential to almost all physiological functions including normal growth, vision, reproduction, embryonic and fetal development, the maintenance of numerous tissues, and overall survival in many species (1). The indispensability of VA has become clear based on the results of feeding VA-deficient diets to animals. The lesions of VA deficiency are multiple but can be reversed by VA administration, further illustrating the important role of this vitamin in nearly every aspect of life. The effects of VA are exerted primarily by regulating the expression of target genes through specific receptors (RA receptors (RAR) and retinoid X receptors (RXR)) (2). Therefore, with respect to the effects of VA on normal growth, VA might exert its action by influencing a number of biochemical and physiological factors controlling growth and cell differentiation.

Insulin-like growth factors (IGF-I and IGF-II, hereinafter IGFs) are important in regulating the growth and differentiation of a variety of tissues $(3,4)$. Both have essential roles in fetal development. IGF-I is of primary importance in terms of nutrient- and hormone-dependent regulation of postnatal growth. It is

* To whom correspondence should be addressed.

E-mail: akatoq@mail.ecc.u-tokyo.ac.jp produced in the liver, secreted into the circulation, and acts on target tissues in an endocrine fashion $(5,6)$. It is also produced in most extra-hepatic tissues and can function as an autocrine and/or paracrine growth stimulator $(5,6)$. The biological actions of IGFs, are mediated by a family of cell-surface receptors that includes the insulin receptor (InR) and type 1 and type 2 IGF receptors (IGF-IR, IGF-IIR, respectively). IGF-I exerts its actions primarily through binding to IGF-IR, and partly through binding to InR (7). Furthermore, the actions of IGFs are modulated by IGF-binding proteins (IGFBPs). IGFBPs bind specifically and with high affinity to IGFs, and have been suggested to act as modulators by either enhancing or inhibiting the activity and bioavailability of IGFs (8).

There is an increasing body of evidence indicating a role for VA in the regulation of gene expression in the IGF system. For example, studies using cell cultures have demonstrated the important effects of RA on the expression of IGFBP genes in many cell lines, including up-regulation or down-regulation, depending on either the cell line or the type of IGFBP (9-13), and on the expression of IGF-I and IGF-II genes by causing a transient mRNA increase in osteoblast cell lines (14). In a VA-deficient system in birds, we found, for the first time in vivo, that the gene expression of the IGF system is greatly affected by VA $(15,16)$. Studies on whether or 
how VA influences gene expression in the IGF systems of mammals, however, have not yet been carried out.

In the present study, to elucidate the relationship between VA and the IGF systems in mammals, we examined the effects of VA deficiency on the serum IGF-I concentrations as well as the expression of IGFs, IGF-IR, and IGFBPs in different rat tissues. We also examined the effects of VA repletion on VA-deficient rats in terms of the expression of these genes.

\section{MATERIALS AND METHODS}

Animals and experimental design. All trans-retinol palmitate and all trans-retinoic acid (RA) were purchased from Sigma (St. Louis, MO, USA). Two different diets, a vitamin A-deficient diet (-VA) and a -VA diet supplemented with $1.35 \mathrm{mg} / \mathrm{kg}$ of all trans-retinol palmitate (+VA), were prepared. In the -VA diet, nutrients other than retinol were sufficient to support normal growth, and the composition of the experimental diets was based on the AIN-76 diet. These two diets were prepared weekly and stored at $-20^{\circ} \mathrm{C}$ until use.

In the first experiment (Exp. 1), male weanling rats of the Wistar strain (3-wk-old) were randomly divided into two groups (control and VA-deficient groups). The rats were kept in a room maintained at $22 \pm 1^{\circ} \mathrm{C}$ with a $12 \mathrm{~h}$ light $/ 12 \mathrm{~h}$ dark cycle (lights turned on at 0800). The VA-deficient group was fed the -VA diet, and the control group was maintained on the +VA diet. The rats were allowed free access to food and water, and were weighed weekly. After being fed the experimental diets for $11 \mathrm{wk}$, five rats of each group were anesthetized with pentobarbital and blood was taken from the carotid artery. Serum was collected and used for measuring the serum retinol and IGF-I concentrations.

In the second experiment (Exp. 2), male weanling rats were fed the +VA or -VA diet for $11 \mathrm{wk}$ as described in Exp. 1. Next, five rats from each group received an ip injection of $2 \mathrm{mg}$ RA (Sigma) or an equal amount of the vehicle, and were sacrificed after the indicated times. RA was dissolved in ethanol $(10 \mathrm{mg} / \mathrm{mL})$ and diluted fivefold using rapeseed oil prior to injection.

In both experiments, tissues including the liver, heart, lungs, kidney, spleen, and testes were quickly dissected, immediately frozen in liquid nitrogen, and stored at $-80^{\circ} \mathrm{C}$ until the analysis of IGF-I, IGF-II, IGFIR, IGFBP-1, IGFBP-3, IGFBP-4, IGFBP-5, and IGFBP-6 mRNA expression. All experiments were performed under the guidelines of the Animal Usage Committee of the Faculty of Agriculture, the University of Tokyo (permission number, 1313 T0011).

Serum retinol and IGF-I concentrations. In order to assess the degree of vitamin A depletion in the VA-deficient group, serum retinol levels were determined by high-performance liquid chromatography (HPLC) as described previously (17-19). Serum concentrations of IGF-I were determined using a RIA kit based on acidethanol extraction (rat IGF-I DSL-2900, Diagnostic Systems Laboratories, Webster, TX, USA) according to the manufacturer's instructions.

Measurement of the expression of genes encoding the IGF system. Preparation and radio-labeling of anti-sense RNA probes: Template DNAs for the synthesis of antisense RNA probes were obtained by RT-PCR. The $5^{\prime}$ ends of the gene-specific sense and anti-sense primers corresponded, respectively, to the following nucleotide positions on the rat gene sequences stored in GenBank under the indicated accession numbers: IGF-I, 225475 (M15480); IGF-II, 296-596 (X02213); IGF-IR, 241-681 (M27293); IGFBP-1, 205-634 (M58634); IGFBP-3, 453-903 (M33300); IGFBP-4, 502-812 (X81582); IGFBP-5, 656-870 (M62781), and IGFBP6, 236-456 (M69055). The amplified cDNAs were subcloned into pGEM-T easy vector (Promega, Madison, WI, USA), and the sequences were confirmed using an automated DNA sequencer (ABI 310). To generate their anti-sense cRNA probes, the plasmids were linearized with Sal 1 or NcoI restriction endonucleases, respectively, and transcribed by T7 or SP6 RNA polymerase in the presence of a $\left[\alpha^{3}{ }^{32} \mathrm{P}\right] \mathrm{UTP}$, as described previously (20).

RNase protection assay. Total RNA was extracted from the liver, heart, lungs, spleen, kidney, and testes using TRIzol reagent (Invitrogen, Carlsbad, CA, USA) according to a previously described method. Sample qualities and quantities were assessed by measuring the optical density of each sample at 260 and $280 \mathrm{~nm}$. Sample quality was also checked by ethidium bromide staining of the denatured agarose gel. Equal amounts of total RNA $(40 \mu \mathrm{g})$ from each sample were then used for determining the expression of IGF-I, IGF-II, IGF-IR, and IGFBP mRNAs by an RNase protection assay, as described previously (21). To compare the equivalent loading of RNA samples, rat GAPDH was used as an internal control.

Data analysis. Hybridized blots were visualized and analyzed using FLA3000 (FujiPhoto Film, Tokyo, Japan). All values for mRNA levels are given relative to controls within an experiment. All data including body weight, serum retinol and IGF-I concentrations, and the mRNA levels of the IGF system gene are expressed as means and SE. One-way ANOVA was used to analyze the effects of diet on the body weight and serum IGF-I concentrations, and gene expression of the IGF system. A post hoc analysis was performed using Fisher's PLSD test (Statview J-4.51.1 for Macintosh, Abacus Concepts, Berkeley, CA, USA). Differences that resulted in $p$-values of $<0.05$ were considered significant.

\section{RESULTS}

\section{Effect of VA deficiency on IGF-I serum levels}

Rats fed the VA-deficient diet had significantly lower body weight $(p<0.05)$ than those fed the control diet (Fig. 1A). VA deficiency was confirmed by depleted concentrations of retinol in the serum $(<12.6 \mathrm{ng} / \mathrm{mL}$, normal level being $240.1 \mathrm{ng} / \mathrm{mL}$, Fig. 1B) and retinyl palmitate in the liver (approximately $1 \%$ of the value for the control group, data not shown). The VA-deficient rats appeared healthy and did not exhibit infection or neurological signs or symptoms. However, the serum IGF-I concentrations were significantly reduced by VA 

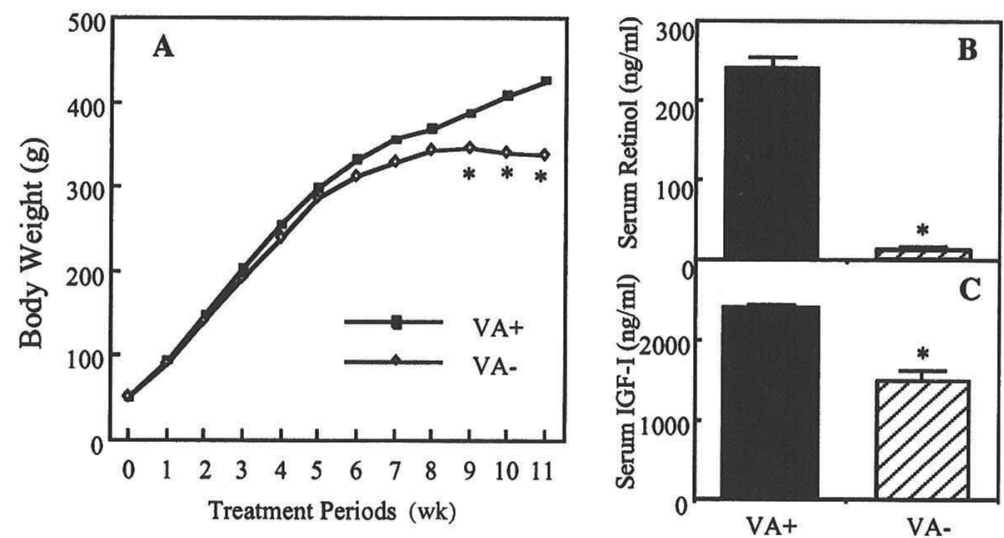

Fig. 1. Influence of vitamin A deficiency on growth and serum insulin-like growth factor (IGF)-I concentration. Rats (3-wk-old) were fed a vitamin A-deficient diet (-VA) or -VA supplemented with $1.35 \mathrm{mg} / \mathrm{kg}$ diet of all-trans retinol palmitate (+VA) for $11 \mathrm{wk}$. Growth curves during this treatment period are shown in A (means \pm SE, $n=15)$. Serum retinol and IGF-I concentrations after $11 \mathrm{wk}$ of treatment are shown in B and C (means $\pm S E, n=5$ ), respectively. *Different from +VA, $p<0.05$.

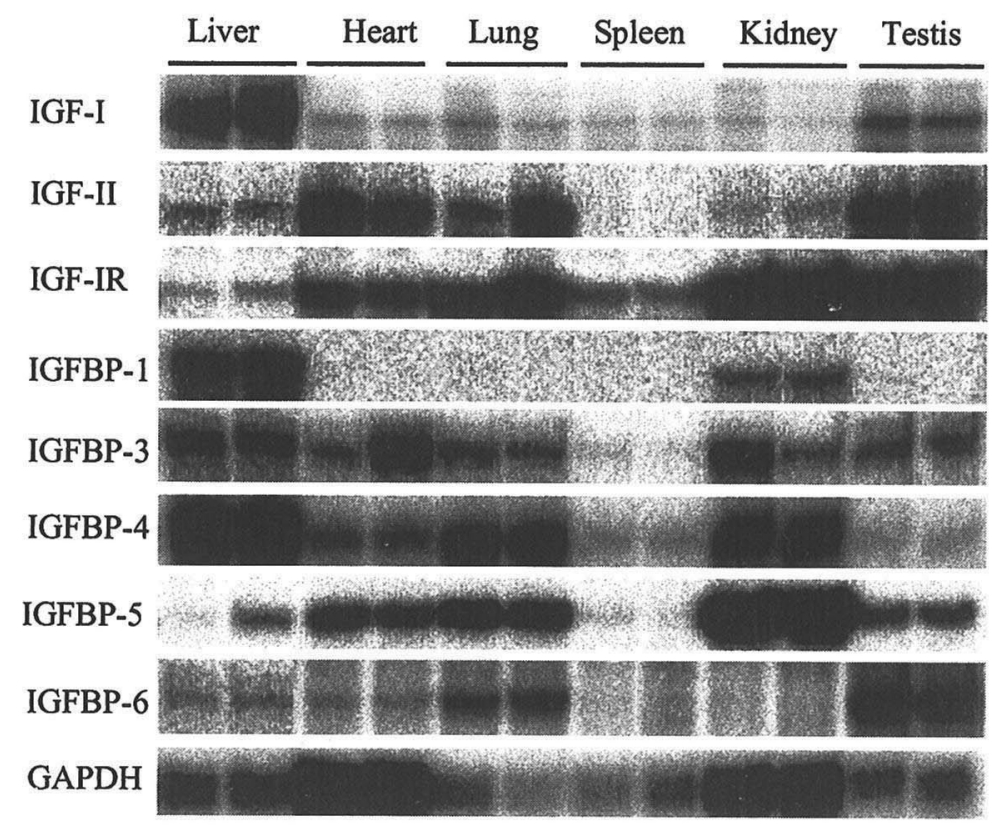

Fig. 2. Tissue distribution of the gene expression of components of the IGF system as determined by RNase protection assay. Total RNA $(40 \mu \mathrm{g})$ isolated from different tissues was hybridized to the respective cRNA probes. Typical results of the assay for IGF-I, IGF-II, IGF-I receptor (IGF-IR) and IGF binding proteins (IGFBP), and glyceraldehyde-3-phosphate dehydrogenase (GAPDH) are shown.

deficiency, being approximately $60 \%$ of the value for the control group ( $p<0.01)$ (Fig. 1C).

Effect of VA deficiency on the expression of IGF, IGF-IR, and IGFBP genes

Prior to examining the effects of VA deficiency on the gene expression of IGF-I, IGF-II, IGF-IR, and IGFBPs, we investigated the tissue distributions of these genes with a RNase protection assay using ${ }^{32} \mathrm{P}$-labeled probes of the respective genes and total RNA extracted from various tissues of the control group. As shown in Fig. 2, the distribution patterns were clearly distinct between these genes. For example, IGF-I, IGFBP-I, and IGFBP4 mRNA levels were higher, whereas IGF-II, IGF-IR, and IGFBP-5 mRNA levels were much lower in the liver than in the heart and lungs.
Based on the information in Fig. 2, we next selected the liver, lungs, heart, and testes to examine the effects of VA deficiency on the expression of these genes. As shown in Fig. 3A, the decrease in the serum IGF-I concentrations induced by VA deficiency (Fig. 1C) was accompanied by a significant decrease in the IGF-I mRNA levels in the liver ( $60 \%$ of the control group, $p<0.05$ ), the tissue secreting the largest proportion of serum IGFI. The reduction in IGF-I mRNA levels caused by VA deficiency was also observed in lung tissue, but not the heart (Fig. 3A) or testes (data not shown). In contrast, VA deficiency caused an increase in IGF-IR mRNA levels (Fig. 3A). However, this up-regulation was observed only in the heart (approximately $200 \%$ of the control group) and not in other selected tissues (Fig. 3 and data 

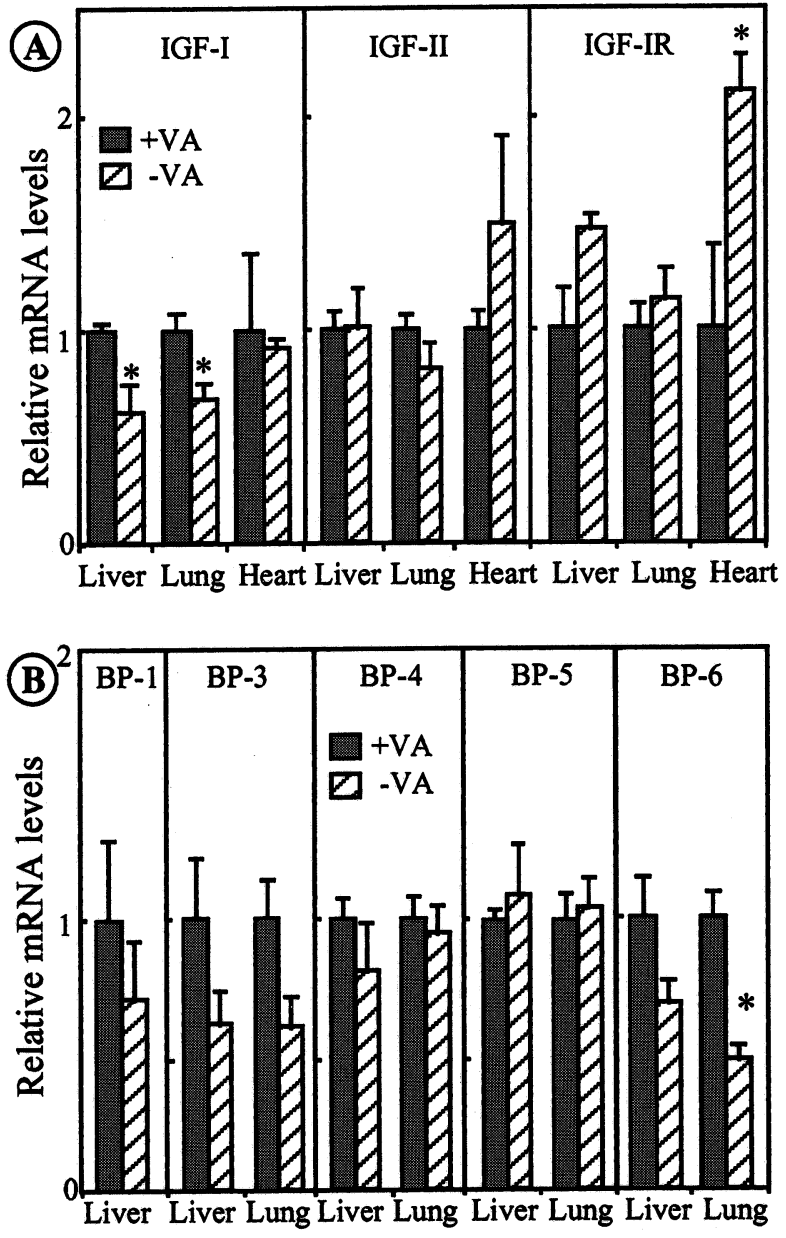

Fig. 3. Effects of vitamin A deficiency on the gene expression of IGF-I, IGF-II, IGF-IR (A), and IGFBPs (B) in several tissues. Rats were maintained as described in the legend of Fig. 1. After feeding the -VA or +VA diet for $11 \mathrm{wk}$, five rats from each treatment group were sacrificed and their tissues were processed for assaying the mRNA levels of each gene. The level of GAPDH mRNA was used as an internal control in the same tissue to normalize the mRNA intensities of each gene. Quantitative results are presented, expressed as values relative to the abundance in the control. Data repre-

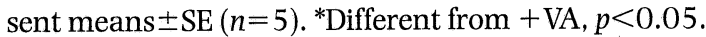

not shown). With respect to IGF-II gene expression, mRNA levels in any of the selected tissues were not affected by VA deficiency (Fig. 3A).

The expression of IGFBP- $1,-4,-5$, and BP- 6 genes in the liver was not affected by VA deficiency (Fig. 3B). In the lungs, VA deficiency did not alter the IGFBP- 4 and IGFBP- 5 mRNA levels, but significantly reduced that of IGFBP- 6 by $60 \%(p<0.01)$ as compared to the control group (Fig. 3B). With regard to IGFBP-3, the most abundant IGFBP in circulation, its expression in the liver and lungs was reduced to about $60 \%$ of the respective control values as the result of VA deficiency, but the differences were not significant $(p>0.05)$. In addition, VA deficiency did not affect the expression of these genes in the heart or testes tissues (data not shown).
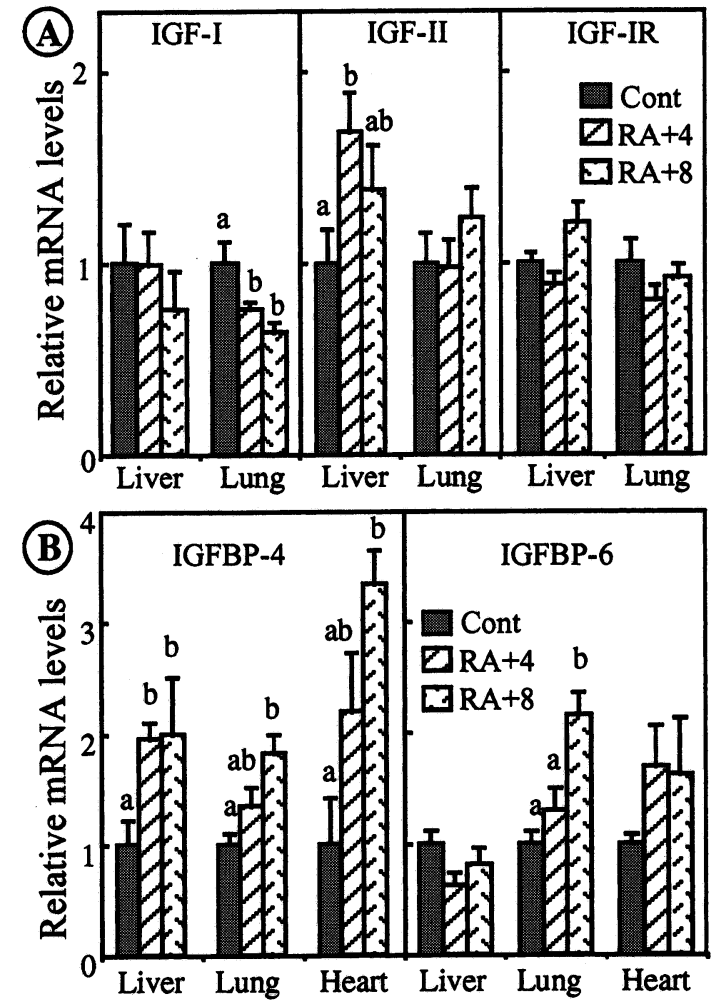

Fig. 4. Injection of retinoic acid (RA) to the VA-deficient rats shows differing regulation of gene expression for IGF-I, IGF-II, IGF-IR, IGFBP-4, and IGFBP-6. Rats were depleted of VA by being fed a VA-free diet for 11 wk. They were sacrificed 4 or $8 \mathrm{~h}$ after treatment with $2 \mathrm{mg} /$ rat of all-trans RA (termed as RA +4 or RA +8 , respectively), and their tissues were processed to measure the mRNA levels of IGFs (IGF-IR (A), IGFBPs (B)) using an RNase protection assay. The level of GAPDH mRNA was used as an internal control in the same tissue to normalize the mRNA intensities of each gene. Quantitative results are presented, expressed as values relative to the abundance in the vehicle treatment (Cont). Data represent means \pm SE $(n=5)$. Means not bearing the same letter are significantly different $(p<0.05)$.

Effect of VA repletion on the expression of IGF, IGF-IR and IGFBP genes

We next examined whether the increase in IGF-IR mRNA levels and the decrease in those of IGF-I and IGFBP- 6 that had been caused by VA deficiency could be restored by an injection of VA. Figure 4 shows the effects of treatment with RA on IGF-I and IGF-IR gene expression in the tissues of the VA-deficient rats. RA injection did not alter the IGF-IR mRNA levels in any of the tissues examined including the heart, whereas IGF-IR mRNA expression was significantly increased by VA deficiency. RA treatment did not restore the decrease in IGF-I mRNA levels in the liver and lungs caused by VA deficiency, but instead caused a further decrease in the lung IGF-I mRNA level. In contrast, with respect to expression of the IGF-II gene, $4 \mathrm{~h}$ after a single injection of $\mathrm{RA}$, the mRNA levels in the liver increased significantly, by approximately $70 \%(p<0.05)$, but not those of the lung (Fig. 4A), heart or testes tissues (data not shown). 


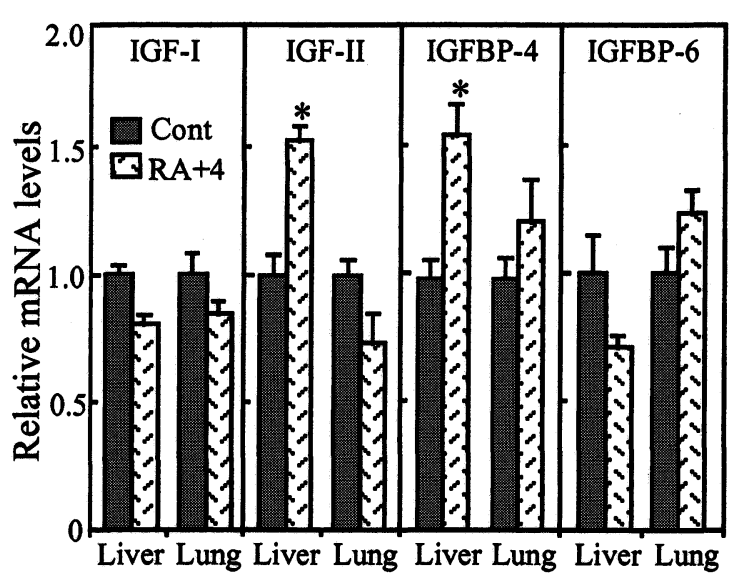

Fig. 5. Injection of RA into VA-sufficient rats induced the over-expression of IGF-II and IGFBP-4 transcripts in the liver. All-trans RA ( $2 \mathrm{mg} / \mathrm{rat})$ was injected into the VA-sufficient rats and they were sacrificed $4 \mathrm{~h}$ later $(\mathrm{RA}+4)$. Their tissues were processed to measure the mRNA levels of IGFs and IGFBPs. The level of GAPDH mRNA was used as an internal control in the same tissue to normalize the mRNA intensities of each gene. Quantitative results are presented, expressed as values relative to the abundance in the vehicle treatment (Cont). Data represent means \pm SE $(n=5)$. *Different from $+\mathrm{VA}, p<0.05$.

Compared with the expression of IGF-I and IGF-IR, IGFBP gene expression was more sensitive to RA treatment. A single injection of RA to the VA-deficient rats significantly increased the IGFBP-4 mRNA level by approximately twofold in the liver and lungs, and by more than threefold in the heart $8 \mathrm{~h}$ after treatment (Fig. 4B). A similar induction in the IGFBP-4 mRNA level was also observed in the liver, but not in the lungs or heart $4 \mathrm{~h}$ after treatment (Fig. 4B). Moreover, the IGFBP-6 mRNA level in the lungs was significantly induced by treatment with RA $8 \mathrm{~h}$ after injection, although no change was observed after $4 \mathrm{~h}$ (Fig. 4B). However, IGFBP-6 gene expression in the liver and heart (Fig. $4 \mathrm{~B})$, and IGFBP-3 and IGFBP-5 gene expression in all tissues examined (data not shown) were not affected by RA treatment.

To further characterize the inductive effects of RA on the expression of IGF-II, IGFBP-4, and IGFBP-6 transcripts, we performed an experiment with the VA-sufficient rats that was similar to that done with the VA-deficient rats. Regardless of the retinoid status, an injection of RA into the VA-sufficient rats also caused a significant increase in IGF-II and IGFBP-4 mRNA levels in the liver after $4 \mathrm{~h}(p<0.01)$ (Fig. 5). In addition, just as in the case of the VA-deficient rats, there was no change in IGFBP-4 expression in the lungs or heart, nor that of IGFBP-3, IGFBP-5, and IGFBP-6 genes in all tissues examined, $4 \mathrm{~h}$ after RA treatment (Fig. 5 and data not shown).

\section{DISCUSSION}

The IGFs and VA are important regulators of a wide range of physiological processes. The important role of
VA in the gene expression of the IGF system has been well documented in many in vitro systems, but rarely in in vivo systems. In the present study, we used an in vivo system (VA-deficient rats) to investigate the regulation of IGF-I, IGF-II, IGF-IR, and IGFBP gene expression by VA in various tissues. This model system has been useful in the past for studying the involvement of VA in many situations, and has shown that VA plays essential roles in a number of biological processes and in the regulation of many genes $(1,22-24)$. In previous studies, we applied this model to Japanese quail, first revealing that the gene expressions of some members of the IGF system are under the control of VA status in birds (15, 16). The present results also indicate that VA status could influence gene expressions in the IGF system of the rat in a species-specific manner, which will be discussed in detail below.

Serum IGF-I concentrations and tissue IGF-I mRNA levels in the rat were found to be decreased by VA deficiency, but were less sensitive to the change in VA status than those observed in Japanese quail (15). In Japanese quail, serum IGF-I concentrations and IGF-I mRNA levels in both the liver and extra-hepatic tissues are significantly decreased in response to the consumption of a VA-deficient diet for $14 \mathrm{~d}$ after hatching, which precedes the decrease in body weight. In contrast, we have obtained preliminary results suggesting that there is no reduction in either the serum IGF-I nor tissue IGF-I mRNA level in response to feeding 3-wk-old rats a VAdeficient diet for $8 \mathrm{wk}$ (data not shown), the time at which VA-deficient rats began to exhibit a retardation in growth rate as shown in Fig. 1. However, feeding the 3-wk-old rats a VA-deficient diet for $11 \mathrm{wk}$ significantly decreased both the serum IGF-I concentration and tissue IGF-I mRNA level (Figs. 1 and 3). With respect to the extra-hepatic tissues, a decrease in the IGF-I mRNA level caused by VA deficiency has been observed in the lung, heart, and testes tissues of Japanese quail (15). In the case of the VA-deficient rats, however, a decrease in the IGF-I mRNA level was observed only in the lungs, and not in the heart and testes tissues (Fig. 3).

Differences in the degree of VA depletion between the VA-deficient rat and the VA-deficient Japanese quail may be one possible explanation for these discrepancies. In Japanese quail, serum retinol and hepatic retinyl palmitate concentrations are reduced by more than $80 \%$ in response to feeding a VA-deficient diet for $14 \mathrm{~d}$, and both are below detectable levels after a 21-d VA-deficient period $(15,25)$. In the case of the rats in this study, serum retinol levels were still detected even though the rats received a VA-deficient diet for $11 \mathrm{wk}$ (an approximate $95 \%$ reduction). Furthermore, the differences in the growth stages between the rat and quail when they were deprived of VA may be another basis for their different responses to the VA status. It is well known that hepatic IGF-I mRNA and serum IGF-I levels increase sharply and remain elevated during rapid growth stages in animals, but then begin to decrease with age. We have reported that, in Japanese quail, the hepatic IGF-I mRNA level rises rapidly during the first 
3 wk after hatching, when the relative growth rate is the highest (26). A rapid depletion of VA occurs during this period, resulting in severe effects on the serum IGFI and tissue IGF-I mRNA levels. In contrast, due to the slower diminution of VA, rats might not suffer from severe VA deficiency in the period of highest growth, resulting in a much smaller impact of VA deficiency on the expression of the IGF-I gene. In fact, it has been reported that the reduction in serum IGF-I level in response to dietary protein restriction is age-dependent (27). When female rats are fed a low-protein diet for $7 \mathrm{~d}$ at different ages, protein restriction causes a dramatic decrease in serum IGF-I in the younger animals, and this effect is progressively attenuated with increasing age. In addition to the two aforementioned possibilities, other unknown factors may also affect this species-specific responsiveness to VA status.

Although IGF-II is considered to be predominantly a fetal growth factor, the results presented in Fig. 2 show an abundant expression of this gene in some tissues even after birth. Hormonal regulation of IGF-II gene expression has been demonstrated in several instances, but the effects of VA deficiency on IGF-II gene expression have not previously been studied in any in vivo system. We therefore also examined the effects of VA deficiency on the expression of this gene in several tissues, including the liver, lungs, heart, and testes. The results of the present study revealed that IGF-II gene expression in these tissues is not influenced by VA deficiency.

The number of receptors present on target cells determines the strength of the IGF signal, and both IGF-I and IGF-II act primarily through the Type I IGF receptor (IGF-IR). It is therefore worth examining how VA deficiency affects IGF-IR mRNA expression in various tissues. Compared to IGF-I gene expression, IGF-IR expression is less sensitive to changes in VA nutritional status. IGF-IR mRNA was found to increase only in the heart, and remained unchanged in the liver, lungs, and testes. The lower sensitivity to and the tissue-specificity of regulation by VA deficiency are also present in Japanese quail (15). For example, a $14 \mathrm{~d}$ feeding of a VA-deficient diet did not affect expression of the IGF-IR gene in any of the tissues examined, although it greatly reduced serum IGF-I and tissue IGF-I mRNA levels in the quail. However, when this diet was given for $21 \mathrm{~d}$, IGF-IR mRNA increased in the heart, kidney, and testis, but not in the liver, brain or lungs. Taken together, these results clearly indicate that IGF-IR mRNA expression is generally up-regulated by VA deficiency, whereas the serum IGF-I concentrations and tissue IGF-I mRNA levels are down-regulated.

The biological activities of IGFs are mediated by their interaction with large soluble proteins (the IGFBPs), of which there are six known to date. Therefore, to clearly understand the physiological role of IGFs in the actions of VA, it is necessary to examine the effects of VA on IGFBP synthesis. Numerous studies on mammals have been dedicated to elucidating the hormonal and metabolic regulation mediating IGFBP expression (28). With the exception of IGFBP-1 and IGFBP-2, little informa- tion is available regarding the expression of IGFBPs in any in vivo system. We previously reported for the first time that the expression of IGFBP-2 and IGFBP-5 genes in Japanese quail is differently affected by changes in the VA nutritional status. For example, VA deficiency causes a significant decrease in the IGFBP-5 mRNA and IGF-I mRNA levels in many tissues (16), but has a negligible effect on IGFBP-2 gene expression. In the present study, we found that rat IGFBPs also respond to VA depletion in gene- and tissue-specific manners (Fig. 3B). Among the IGFBPs examined, the effects of VA deficiency were limited to IGFBP- 6 mRNA in the lung tissue, where a significant decrease in expression was observed. We previously reported that IGFBP-5 expression is very sensitive to the change in VA status in Japanese quail; this expression did not, however, change in the VA-deficient rats in the present study. These results suggest the existence of a species-specific regulatory mechanism for IGFBP genes in response to VA deficiency, at least in the case of IGFBP-5.

It has been reported that starvation-induced changes in serum IGF-I concentration, hepatic IGF-I mRNA level, and tissue IGF-IR mRNA level can be partly or completely restored to control levels by short-term refeeding. For example, Kita et al. (29) reported that serum IGF-I concentration and hepatic IGF-I gene expression are fully restored in chickens within $2 \mathrm{~h}$ of refeeding after food deprivation. Therefore, in the present study, a single dose of RA was given to the VA-deficient rats to examine the short-term effects of RA on gene expression of the IGF system in various tissues. Our finding of no restoration in IGF-I and IGF-IR mRNA levels is in agreement with our previous report regarding Japanese quail (15). It is therefore not reasonable to postulate that the regulation of genes for IGF-I and IGFIR by retinoid occurs directly by the binding of retinoid receptors to a RA-responsive element (RARE). In fact, no RARE has ever been reported in the promoter regions of these genes. In contrast, a single injection of RA was found to rapidly induce IGF-II mRNA expression, although the expression of this gene is not altered by VA deficiency. This inductive effect of RA on IGF-II gene expression appears to be specific to the liver. Furthermore, administration of RA to the control (VAsufficient) rats also rapidly induced IGF-II mRNA expression in the liver. Enhanced IGF-II mRNA expression as a result of RA treatment has also been described for osteoblast cell lines (14) and several neuroblastoma cell lines (30-32). The mechanisms by which RA acts, or the identification of specific responsive elements that may be involved in regulation, however, remain elusive.

A number of studies have demonstrated the important effects of RA on IGFBP expression in many cell lines including up- and down-regulation, which depend on either the cell line or the type of IGFBP (9-13). In an in vivo system used for Japanese quail, we previously found that RA can rapidly induce IGFBP-5 mRNA expression (16). The present results indicate that the link between VA and IGFBP genes exists not only in birds, but also in mammals. Of the IGFBPs investigated in this 
study, RA treatment enhanced the gene expression of IGFBP-4 and IGFBP-6. The induction of IGFBP-4 expression appeared in all the tissues examined, while the increase in IGFBP-6 expression was observed only in the lungs, where a decrease in the expression of this gene in response to VA deficiency was observed. However, the rapid induction of IGFBP-5 gene expression in response to RA treatment, which is observed in Japanese quail, was not seen in the rat. These results suggest that gene-, tissue-, or species-specific mechanisms might underlie the expression of IGFBP genes as regulated RA.

As described in the introduction, both the IGF system and VA are important in growth regulation. The present study shows that growth retardation as the result of VA deficiency is accompanied by a change in the IGF system, such as reductions in the level of serum IGF-I and tissue mRNA contents of IGF-I and IGFBP-6. Furthermore, VA repletion induced the expression of some components of the IGF system. Thus, VA may exert, at least partly, its growth-supportive action by influencing the IGF system.

In conclusion, the results presented here clearly indicate that dietary VA levels modulate serum IGF-I concentration and the gene expression of components of the IGF system in the rat. The reduction in mRNA level or the induction of mRNA expression caused by VA depletion or repletion, respectively, suggests that alterations in the IGF system may mediate some part of the physiological actions of VA in the rat.

\section{Acknowledgments}

This work was supported by a Grant-in-Aid for Scientific Research (No. 12460054) to H.K. from the Japan Society for the Promotion of Science.

\section{REFERENCES}

1) Hofmann C, Eichele G. 1994. Retinoids in development. In: The Retinoids: Biology, Chemistry, and Medicine (Sporn MB, Roberts AB, Goodman DS, eds), 2nd ed, p 387-441. Raven Press, New York.

2) Mangelsdorf DJ, Umesono K, Evans RM. 1994. The retinoid receptors. In: The Retinoids: Biology, Chemistry, and Medicine (Sporn MB, Roberts AB, Goodman DS, eds), 2nd ed, p 319-349. Raven Press, New York.

3) Stewart CE, Rotwein P. 1996. Growth, differentiation, and survival: multiple physiological functions for insulin-like growth factors. Physiol Rev 76: 1005-1026.

4) Werner H, LeRoith D. 1996. The role of the insulin-like growth factor system in human cancer. Adv Cancer Res 68: $183-223$.

5) D'Ercole AJ, Stiles AD, Underwood LE. 1984. Tissue concentrations of somatomedin $\mathrm{C}$ : further evidence for multiple sites of synthesis and paracrine or autocrine mechanisms of action. Proc Natl Acad Sci USA 81: 935-939.

6) Daughaday WH. 1989. Somatomedins: a new look at old questions. In: Molecular and Cellular Biology of Insulin-Like Growth Factors and Their Receptors (LeRoith D, Raizada MK, eds), p 1-4. Plenum Press, New York.
7) Nissley P, Lopaczynski W. 1991. Insulin-like growth factor receptors. Growth Factors 5: 29-43.

8) Jones JT, Clemmons DR. 1995. Insulin-like growth factors and their binding proteins: biological actions. Endocr Rev 16: 3-34.

9) Dong Y, Canalis E. 1995. Insulin-like growth factor (IGF) I and retinoic acid induce the synthesis of IGF-binding protein 5 in rat osteoblastic cells. Endocrinology 136: 2000-2006.

10) Glantschnig H, Varga F, Klaushofer K. 1996. Thyroid hormone and retinoic acid induce the synthesis of insulin-like growth factor-binding protein-4 in mouse osteoblastic cells. Endocrinology 137: 281-286.

11) Zhou Y, Mohan S, Linkhart TA, Baylink DJ, Strong DD. 1996. Retinoic acid regulates insulin-like growth factor-binding protein expression in human osteoblast cells. Endocrinology 137: 975-983.

12) Chambery D, de Galle B, Babajko S. 1998. Retinoic acid stimulates IGF binding protein (IGFBP)- 6 and depresses IGFBP-2 and IGFBP-4 in SK-N-SH human neuroblastoma cells. J Endocrinol 159: 227-232.

13) Shang Y, Baumrucker CR, Green MH. 1999. Signal relay by retinoic acid receptors alpha and beta in the retinoic acid-induced expression of insulin-like growth factor-binding protein-3 in breast cancer cells. J Biol Chem 274: 18005-18010.

14) Gabbitas B, Canalis E. 1997. Retinoic acid regulates the expression of insulin-like growth factors I and II in osteoblasts. J Cell Physiol 172: 253-264.

15) Fu ZW, Noguchi T, Kato H. 2001. Vitamin A deficiency reduces IGF-I gene expression and increases IGF-I receptor and insulin receptor gene expression in tissues of Japanese quail (Coturnix coturnix japonica). J Nutr 131: 1189-1194.

16) Fu ZW, Noguchi T, Kato H. 2001. Differential regulation of IGFBP-2 and IGFBP-5 gene expression by vitamin A status in Japanese quail. Am J Physiol 281: E138-E146.

17) Fu ZW, Kato H, Sugahara K, Kubo T. 1998. Vitamin A deficiency reduces the responsiveness of pineal gland to light in Japanese quail (Coturnix japonica). Comp Biochem Physiol 119A: 593-598.

18) Fu ZW, Kato H, Kotera N, Sugahara K, Kubo T. 1999. regulation of the expression of serotonin $\mathrm{N}$-acetyltransferase gene in Japanese quail (Coturnix japonica): II. Effect of vitamin A deficiency. J Pineal Res 27: 34-41.

19) Fu ZW, Kato H, Sugahara K, Kubo T. 2000. Retinoic acid accelerates the development of reproductive organs and egg production in Japanese quail (Coturnix coturnix japonica). Biol Reprod 63: 1795-1800.

20) Matsumura Y, Domeki M, Sugahara K, Kubo T, Roberts CT Jr, LeRoith D, Kato H. 1996. Nutritional regulation of insulin-like growth factor-I receptor mRNA levels in growing chickens. Biosci Biotechnol Biochem 60: 979-982.

21) Fu ZW, Kubo T, Sugahara K, Noguchi T, Kato H. 2001. Cloning of complementary deoxyribonucleic acids encoding quail (Coturnix coturnix japonica) retinoic acid receptor $\beta$ isoforms and changes in their gene expression during gonadotropic growth. Biol Reprod 64: 231-241.

22) Thompson JN, Howell JM, Pitt GAJ. 1964. Vitamin A and reproduction in rats. Proc Roy Soc Biol 159: 510-535.

23) Thompson JN, Howell JM, Pitt GAJ, McLaughlin CI. 
1969. The biological activities of retinoic acid in the domestical fowl and effects of vitamin A deficiency on the chick embryo. Br J Nutr 23: 471-490.

24) Zile MH. 1998. Vitamin A and embryonic development: an overview. J Nutr 128: 455S-458S

25) Fu ZW, Kubo T, Sugahara K, Noguchi T, Kato H. 2001. Retinoid nutritional status differently affects the expression of Japanese quail retinoic acid receptor- $\beta$ isoform transcripts in a tissue-specific manner. $J$ Endocrinol 169: 281-290.

26) Fu ZW, Kubo T, Noguchi T, Kato H. 2001. Developmental changes in the mRNA levels of IGF-I and its related genes in the reproductive organs of Japanese quail (Coturnix coturnix japonica). Growth Horm IGF Res 11: 24-33.

27) Fliesen T, Maiter D, Gerard G, Underwood LE, Maes M, Ketelslegers JM. 1989. Reduction of serum insulin-like growth factor-I by dietary protein restriction is age dependent. Pediatr Res 26: 415-419.

28) Thissen JP, Ketelslegers JM, Underwood LE. 1994.
Nutritional regulation of insulin-like growth factors. Endocr Rev 15: 80-101.

29) Kita K, Hangsanet K, Shibata T, Conlon MA, Sasaki T, Saito N, Okumura J. 1998. Refeeding increases hepatic insulin-like growth factor-I (IGF-I) gene expression and plasma IGF-I concentration in fasted chicks. $\mathrm{Br}$ Poult Sci 39: 679-682.

30) Babajko S, Binoux M. 1996. Modulation of retinoic acid of insulin-like growth factor (IGF) and IGF binding protein expression in human SK-N-SH neuroblastoma cells. Eur J Endocrinol 134: 474-480.

31) Matsumoto K, Gaetano C, Daughaday WH, Thiele CL. 1992. Retinoic acid regulates insulin-like growth factor II expression in a neuroblastoma cell line. Endocrinology 130: 3669-3676.

32) Melino G, Stephanou A, Annicchiarico-Petruzzelli M, Knight RA, Finazzi-Agro A, Lightman SL. 1993. Modulation of IGF-2 expression during growth and differentiation of human neuroblastoma cells: retinoic acid may induce IGF-2. Neurosci Lett 151: 187-191. 